\title{
PROJECT MANAGER SELECTION BY ANALYTIC HIERARCHY PROCESS
}

\begin{abstract}
It is critical to manage the projects that have a regenerative effect in maintaining the strategic goals of organizations. "Who will manage the project with limited time, budget and scope" and "what criteria this manager will have" affect the strategic progress of the organization. Therefore, it is a vital stage "how the project managers in an organization will be selected according to what criteria". In the study, we evaluated the different project manager by using Analytic Hierarchy Process (AHP) method. First, we determined five main criteria and 12 sub-criteria. Then, the algorithm of the AHP method is applied. Finally, alternatives are ranked according to their overall importance weight in descending order.
\end{abstract}

Keywords: project, project manager, decision making, AHP.

\section{Introduction}

A project is a unique process that is independent from the organization in which it is involved, has a limited scope and a certain start and finish time with a limited budget (Liikamaa, K., 2015). The aims of a project are related to the strategic goals of the organization, the contents of these aims are clear and qualitative. The project is a process that is carried out in a unique structure and integrity where many resources, including human, are brought together with a specific purpose for important changes in an organization (Cleland and Kerzner, 1985). Project management uses the knowledge, skills, techniques, and tools together by trying to achieve the results determined as the goal at the expected time of the project without exceeding the planned budget.

There are many components involved in the realization of a successful project, and the competence of the project manager is a very important factor (Fortune and White, 2006). Project managers play a very important role in every stage of the project, especially the project managers are expected to be completed at the desired time, with the desired quality and with the allocated budget. Therefore, it is an important step to identify and select the appropriate project manager at the beginning.

Selecting a project manager for a project is a fundamental decision. Traditionally, the project manager is selected by the top managers of the relevant organization with interviews and references. Selection of project manager consists different criteria and needs to use a suitable decision method. In this study, AHP (Analytic Hierarchy Process) is used as a MCDM (Multiple Criteria Decision Making) method for selecting project manager. AHP is a technique that can be used to deal with complexity when decisions are complex (Saaty, 1980), where: Analytic means that the problem is broken down into its subcomponents; Hierarchy denotes that sub-components of the problem are listed in a 
hierarchical structure according to the main purpose; Process refers to the calculations and evaluations made with the data to reach the final decision step by step.

\section{Literature Review}

Al-Harbi (2001) used the AHP method as a potential decision-making method to be used in project management, he used prequalification of contractor as a problem. Keren et al., (2014) by using Data Envelopment Analysis and the AHP methods together, aimed to rank the project manager candidates according to the criteria. Torfi and Rashidi (2011) used AHP and Fuzzy TOPSIS methods together for selection of a project manager to be assigned to a construction company in their article. Varajão and Cruz-Cunha (2013) proposed the combined usage of the AHP and the ICB as a tool to make decisions in the selection of the project managers. Çelikbilek (2017) proposed the Grey-AHP method for selecting a project manager to be assigned to a software project in an energy company.

\section{Application}

In the application section, a project manager selection problem is handled by AHP method. First, we determined five main criteria and 12 sub-criteria to evaluate three different alternatives. The criteria are: $\operatorname{Basic} \operatorname{criteria}\left(C_{1}\right)$, education $\left(C_{1.1}\right)$, experience $\left(C_{1.2}\right)$, demographic features $\left(C_{1.3}\right)$, criteria of authority $\left(C_{2}\right)$, leadership criteria $\left(C_{2.1}\right)$, managerial criteria $\left(C_{2.3}\right)$, technical criteria $\left(C_{3}\right)$, knowledge $\left(C_{3.1}\right)$, ability $\left(C_{3.2}\right)$, certification criteria $\left(C_{4}\right)$, certificate on the project management $\left(C_{4.1}\right)$, certificate on the $\operatorname{subject}\left(C_{4.2}\right)$ and human criteria $\left(C_{5}\right)$, communication $\left(C_{5.1}\right)$, attitude $\left(C_{5.2}\right)$, character $\left(C_{5.3}\right)$. Then, we organize the problem as a hierarchy. After hierarchical structure are organized, experts from human resources department, set up pairwise comparison matrices of the hierarchy and importance of the criteria and the alternatives are calculated. Three different experts evaluated the hierarchical structure by joint decision. Table 1 shows the joint pairwise comparison matrix of main criteria and calculation results of the importance weights. The other relative importance of the main criteria and sub criteria can be computed as seen in Table 2.

Table 1. Pairwise comparison matrix of the main criteria

\begin{tabular}{ccccccc}
\hline & $C_{1}$ & $C_{2}$ & $C_{3}$ & $C_{4}$ & $C_{5}$ & Weights of the criteria \\
\hline$C_{1}$ & 1 & 4 & 3 & 5 & 7 & 0.457 \\
$C_{2}$ & $1 / 4$ & 1 & $1 / 3$ & 3 & 5 & 0.150 \\
$C_{3}$ & $1 / 3$ & 3 & 1 & 6 & 5 & 0.273 \\
$C_{4}$ & $1 / 5$ & $1 / 3$ & $1 / 6$ & 1 & 3 & 0.077 \\
$C_{5}$ & $1 / 7$ & $1 / 5$ & $1 / 5$ & $1 / 3$ & 1 & 0.041 \\
\hline
\end{tabular}

Consistency Ratio: 0.09

Table 2. Relative importance of the main criteria and sub criteria

\begin{tabular}{llll}
\hline$C_{1}=0.457$ & $C_{1.1}=0.109$ & $C_{2.2}=0.309$ & $C_{3.1}=0.581$ \\
$C_{2}=0.150$ & $C_{2.1}=0.333$ & $C_{2.2}=0.666$ & \\
$C_{3}=0.273$ & $C_{3.1}=0.250$ & $C_{3.2}=0.750$ & \\
$C_{4}=0.077$ & $C_{4.1}=0.250$ & $C_{4.2}=0.750$ & \\
$C_{5}=0.041$ & $C_{4.1}=0.163$ & $C_{4.2}=0.297$ & $C_{4.3}=0.538$ \\
\hline
\end{tabular}


At the last step, final decision matrix is established, and the overall importance weights are computed of alternatives. The overall importance weights of alternatives are calculated as seen in Table 3.

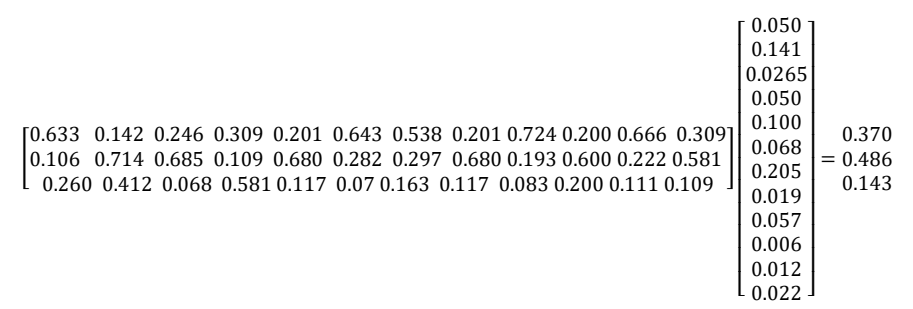

Table 3. The overall importance weights of the alternatives.

According to the overall importance weights of alternatives, the ranking of alternatives is $A_{2}>A_{1}>A_{3}$.

\section{Conclusions}

In this paper we handled the project manager selection problem with AHP. We determined five main criteria and 12 sub-criteria to evaluate three different alternatives. To this aim, we established a four-level hierarchy to identify the problem in more detail. Then, the pairwise comparison matrices are established, and the relative importance of the main criteria and sub criteria are computed. In the last step, the overall importance weights of the alternatives are calculated, and alternatives are ranked in descending order. We conclude that AHP can easily the handle the project manager selection problem.

\section{Key References}

Al-Harbi, K.M.A., (2001). Application of the AHP in project management, International Journal of Project Management, 19, 19-27.

Cleland, D.I., \& Kerzner, H. (1985) A project management dictionary of terms. New York. Van Nostrand Reinhold.

Çelikbilek. Y. (2017). A grey analytic hierarchy process approach to project manager selection, Journal of Organizational Change Management, 31(3), 749-765.

Fortune, J., \& White, D. (2006), Framing of project critical success factors by a systems model. International Journal of Project Management, 24(1), 53-65.

Liikamaa, K. (2015). Developing a project manager's competencies: A collective view of the most important competencies. Procedia Manufacturing, 3, 681-687.

Saaty, T. L. (1980). The Analytic Hierarchy Process. New York: McGraw-Hill.

Torfi, F., \& Rashid, A. (2011) Selection of Project Managers in Construction Firms Using Analytic Hierarchy Process (AHP) and Fuzzy Topsis: A Case Study. Journal of Construction in Developing Countries, 16(1), 69-89. 
Varajão, J., \& Cruz-Cunha, M.M. (2013). Using AHP and the IPMA Competence Baseline in the project managers selection process, International Journal of Production Research, 51(11), 3342-3354. 